\title{
Pemanfaatan Umbi Porang (Amorphophallus muelleri Bl) Sebagai Bahan Baku Keripik
}

\author{
${ }^{1 *}$ Khurin In Wahyuni, ${ }^{2}$ Martina Kurnia Rohmah, ${ }^{3}$ Yani Ambari, ${ }^{4}$ Bagus Kurniawan Romadhon \\ Universitas Negeri Malang; Jalan Semarang 5 Malang \\ *Corresponding author: khurinain87@gmail.com
}

\begin{abstract}
Abstrak
Pemanfaatan porang lebih lanjut membutuhkan teknologi untuk menghilangkan senyawa kalsium oksalat sehingga pemanfaatan porang kedepannya dapat lebih maksimal. Masyarakat Desa Rejosari mengharapkan umbi porang dapat dikelola sendiri menjadi suatu produk makanan karena selama ini masyarakat rejosari hanya menjual porang dalam bentuk umbi mentah. Dengan adanya pelatihan pembuatan kripik dari umbi porang diharapkan dapat membantu perekonomian masyarakat Desa Rejosari. Kegiatan dilakukan melalui dua tahap, yaitu pengolahan umbi porang agar tidak menghasilkan rasa gatal sampai menajdi bahan baku keripik (pengumpulan bahan, perendaman bahan, proses pengeringan dan pengukusan) dan tahap kedua, pengolahan umbi porang menjadi keripik. Dari kegiatan ini diperoleh hasil 85 persen masyarakat Desa Rejosari telah berhasil membuat keripik dari Umbi Porang dan tidak merasakan efek gatal.
\end{abstract}

Kata kunci-Keripik, Porang, Pangan, Umbi.

\section{Abstract}

The use of porang further requires technology to remove iron oxalate so that future utilization of porang can be maximized. The people of Rejosari Village hope that porang tubers can be managed themselves into food products because so far the Rejosari community only sells porang in the form of raw tubers. With training on making chips from porang tubers, they are expected to be able to help the people of Rejosari Village. Activities carried out through two cups, namely processing porang tubers so as not to cause fear until they become raw material for chips (collecting materials, soaking, digging and steaming) and the second process, processing porang tubers into chips. From this activity, 85 percent of Rejosari Village residents have succeeded in making chips from the Porang Bulbs and did not experience any adverse effects.

Keywords-Bulbs, Chips, Food, Porang

\section{PENDAHULUAN}

$\mathrm{D}$ esa Rejosari terletak di sebelah utara Desa Bleberan, sebelah selatan, barat, dan timur dikelilingi oleh hutan. Luas Desa Rejosari 51,8 Ha dengan tipologi dataran tinggi. Desa Rejosari memiliki banyak tanaman yang berpotensi untuk meningkatkan ekonomi masyarakat namun masyarakat belum dapat mengolah tanaman yang tumbuh di sekitar lingkungan sebagai bahan pangan seperti tanaman porang yang merupakan komoditas utama. Porang (Amorphopha-llusmuelleri Blume) adalah golongan Araceae asli Indonesia yang banyak tumbuh di hutan-hutan pulau Jawa, sehingga di Jepang dikenal sebagai "Jawa Mukago Konyaku". Porang mengandung glukomanan yang sangat tinggi (hingga mencapai 65 persen). Kandungan glukomanan porang lebih tinggi dibanding varietas komersial Jepang yaitu konjac atau konnyaku (Amorphophallus konjac) yang hanya 44 persen (Arifin, 2001). Kandungan glukomanan yang tinggi tersebut sangat potensial dimanfaatkan sebagai bahan pangan khususnya dalam menunjang ketahanan pangan nasional (Sutrisno, 2011). Glaukomanan yang terkandung pada umbi porang kering sekitar $15 \%$ $64 \%$ dapat dimanfaatkan sebagai bahan baku makanan maupun kesehatan. Umbi porang mengandung serat tinggi dan rendah kolesterol sehingga dapat dikonsumsi penderita hipertensi dan kencing manis (Faridah \& Widjanarko, 2014; Sutriningsih \& Ariani, 2017). Pemanfaatan porang sebagai bahan pangan di Indonesia terkendala oleh kandungan Kalsium Oksalat yang cukup tinggi yaitu 0,19\% (Dewanto \& Purnomo, 2009). Kalsium Oksalat berupa kristal jarum menyebabkan rasa gatal, iritasi dan gangguan kesehatan lain ketika 
dikonsumsi serta dapat menyebabkan penumpukan di ginjal apabila pengolahannya salah (Maulina dkk., 2012; Chotimah dkk., 2013). Kalsium Oksalat dapat dihilangkan dengan cara perendaman dengan $\mathrm{NaCl} 8 \%$ pada perebusan $80^{\prime} \mathrm{C}$ selama 25 menit, (Widari \& Rasmito, 2018) namun $\mathrm{NaCl}$ murni yang diperlukan susah didapat oleh masyarakat sehingga proses menghilangkan Kalsium Oksalat dilakukan dengan metode gabungan perendaman garam gosrok dan abu. Masyarakat Desa Rejosari Setiap bulan menghasilkan kurang lebih 3 Ton namun hanya dapat menjual porang dalam bentuk umbi segar dengan rata-rata penjualan 6500 per $\mathrm{kg}$, harga tersebut masih belum membantu perekonomian penduduk sekitar sehingga masyarakat berharap dapat mengolah umbi porang secara mandiri. Dengan adanya pengabdian masyarakat ini diharapkan dapat membantu masyarakat untuk mengolah porang tersebut serta mengembangkan porang untuk dijadikan produk olahan.

\section{METODE}

Dalam mengolah umbi porang agar dapat menghasilkan produk makanan maka terlebih dahulu harus menghilangkan rasa gatal akibat Kalsium Oksalat dengan cara optimasi sampai mendapatkan hasil yang terbaik. Pengolahan umbi porang secara umum ada empat tahap yaitu perendaman, penjemuran, pengukusan dan penggorengan sampai menjadi kripik porang, tahapan dalam pembuatan keripik porang adalah sebagai berikut: Porang seberat $5 \mathrm{Kg}$ dikupas dengan ukuran 3-4 inchi kemudian irisan umbi porang dicuci dengan air mengalir serta ditiriskan, potongan porang bagian tengah ditusuk garpu kemudian direndam dalam air yang telah ditambah dengan garam gosrok (300 gram), Direndam selama 3-4 hari dengan penggantian air setiap hari, saat perendaman porang juga diluluri kapur njet (500 gram), setelah proses perendaman selesai maka porang dicuci dengan air mengalir, setelah porang dicuci maka porang kembali direndam dengan air garam sedikit (100 gram) serta porang diluluri dengan abu (500 gram) dan direndam selama 2-3 hari, setelah proses perendaman, porang dicuci dengan air mengalir hingga bersih kemudian dijemur selama 3-4 hari, porang yang telah kering dikukus selama 3 jam dan dijemur kembali 3-4 hari kemudian porang yang telah kering dapat digoreng sampai menjadi keripik porang.

Setelah berhasil membuat keripik porang maka dilakukan penyuluhan, demonstrasi serta pendampingan. Penyuluhan dan demonstrasi di hadiri $30 \mathrm{ibu}$ - ibu PKK dengan tempat di Balai Desa Rejosari. Beberapa peserta yang tertarik terhadap pengolahan umbi porang menjadi keripik dapat mengajukan pendampingan ke rumah-rumah kepada tim pengabdian masyarakat.

\section{HASIL DAN PEMBAHASAN}

Kegiatan penyuluhan ini dilaksanakan di Balai Desa Rejosari. Kegiatan ini bertujuan untuk memberikan informasi terkait cara pengolahan umbi porang yang benar agar tidak menimbulkan rasa gatal saat di konsumsi. Kendala dari kegiatan ini yaitu jadwal pelaksanaan yang tidak sesuai dengan susunan acara sehingga pelaksanaan tidak berjalan dengan maksimal. Namun, informasi terkait cara pengolahan umbi porang yang benar agar tidak menimbulkan rasa gatal saat di konsumsi sudah disampaikan dengan baik kepada Ibu-ibu PKK. Dengan adanya informasi ini, diharapkan warga dapat mengolah porang dengan baik serta dapat mengembangkan umbi porang menjadi produk unggulan Desa Rejosari.

Optimasi pengolahan umbi porang dilakukan selama dua minggu dimulai dari persiapan bahan (Gambar 1) sampai berhasil mendapatkan keripik porang yang dapat dikonsumsi. Pelaksanaan pengabdian masyarakat ini dihadiri sebanyak 30 peserta (Gambar 2), penyuluhan dilakukan dengan media leaflet serta powerpoint, pendemonstrasian (Gambar 3) hanya berupa penggorengan keripik porang, acara penyuluhan ini juga dilengkapi dengan tanya jawab (Gambar 4), 85\% dari total peserta menginginkan pendampingan ke rumahrumah agar lebih memahami pengolahan porang (Gambar 5). Hasil keripik porang sudah dapat dinikmati oleh para peserta dan tidak menimbulkan rasa gatal. Pada peserta pendampingan yang mengolah porang di rumah juga dilaporkan tidak mengalami gejala yang membahayakan terkait pengkonsumsian keripik porang. Terdapat sedikit kendala terkait hasil dari keripik porang yaitu nilai estetika yang kurang menarik karena bekas rendaman abu menyebabkan keripik porang berwarna agak kehitaman. Evaluasi yang dilakukan adalah memberikan rasa seperti barbeque, balado, keju sehingga tidak hanya rasa yang lebih enak namun penampilan keripik porang lebih baik. 


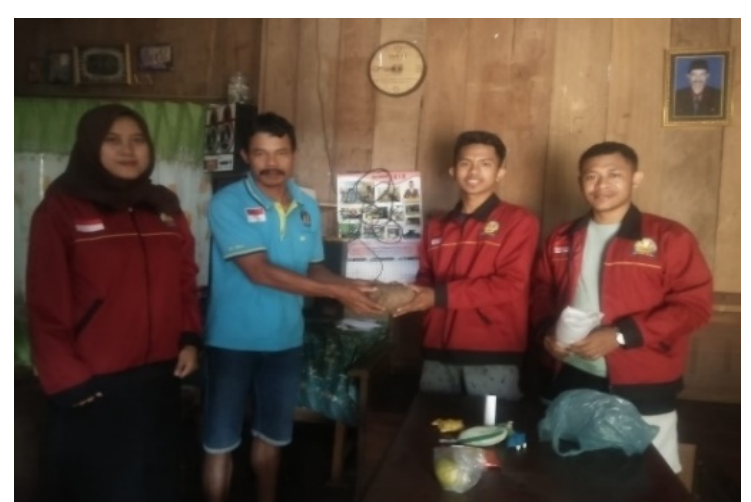

Gambar 1. Kegiatan Penyerahan secara Simbolis dari Perangkat Desa Kepada Mahasiswa

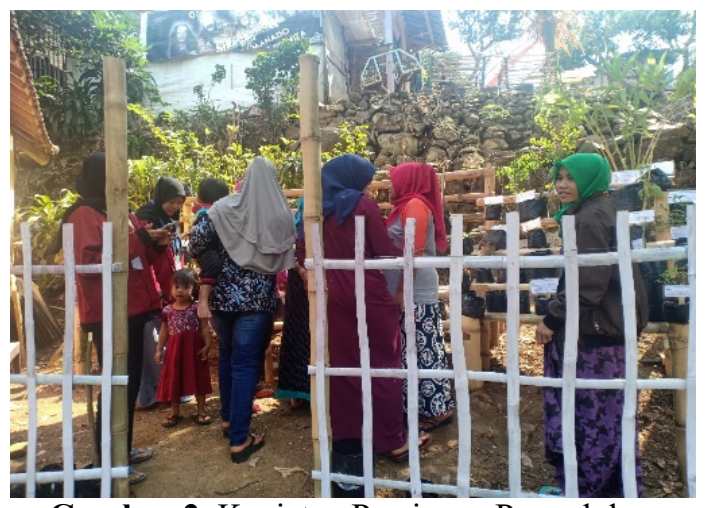

Gambar 2. Kegiatan Persiapan Penyuluhan

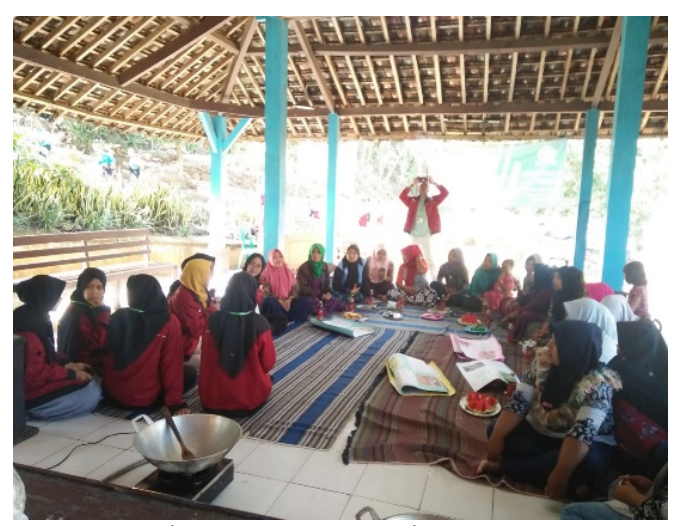

Gambar 3. Kegiatan Demonstrasi Penggorengan Keripik

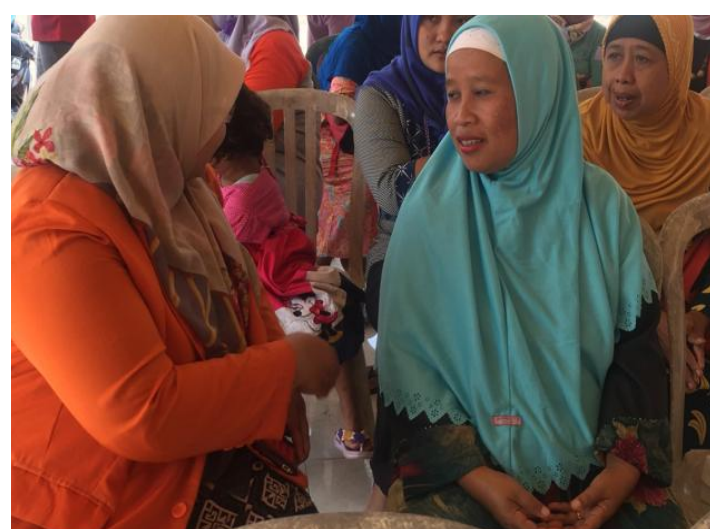

Gambar 4. Tanya Jawab dengan Ibu-ibu PKK

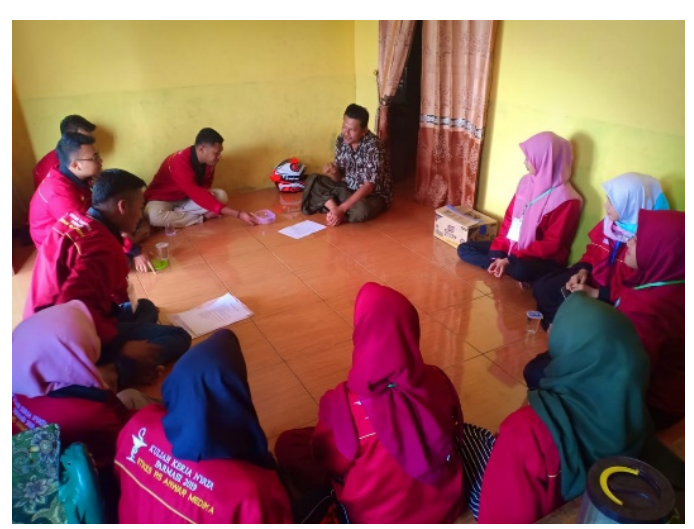

Gambar 5. Pendampingan ke Rumah Penduduk

\section{SIMPULAN}

Desa Rejosari Kecamatan Jatirejo, Mojokerto memiliki potensi tanaman yang dapat diolah sehingga dapat membantu perekonomian penduduk sekitar salah satunya adalah tanaman porang, selama ini masyarakat hanya dapat menjual umbi porang dalam bentuk mentahan karena belum dapat mengolah porang menjadi produk jadi, kelemahan umbi porang adalah tingginya kalsium oksalat yang dapat menyebabkan iritasi, gatal dan bila salah dalam pengolahannya dapat mengendap dalam ginjal. Kalsium Oksalat Umbi Porang dapat dihilangkan melalui beberapa tahapan yaitu perendaman dengan garam grosok, kapur njet dan arang, untuk membuat produk olahan yaitu keripik maka memerlukan waktu yang cukup lama mulai dari persiapan, perendaman, pengeringan, pengukusan sampai penggorengan. Keripik porang yang dihasilkan sudah aman dikonsumsi namun tampilan atau estetika keripik masih kurang menarik karena bekas rendaman arang sehingga untuk kedepannya dapat ditambahkan perasa dan pewarna makanan untuk meningkatkan rasa dan tampilan.

\section{UCAPAN TERIMAKASIH}

Terima kasih kepada mitra masyarakat Desa Rejosari Kecamatan Jatirejo dalam pelaksanaan kegiatan pengabdian masyarakat atas kerjasama dan juga kepada pihak STIKES RS Anwar Medika yang telah memberikan support luar biasa serta mahasiswa yang berperan aktif dalam pengabdian masyarakat ini.

\section{DAFTAR RUJUKAN}

Arifin. (2001). Pengeringan Umbi Iles-Iles Secara Mekanik Untuk Meningkatkan Mutu Keripik Iles-iles. 
Chotimah, S., Fajarini, D. T., \& Budiyati, C. S. (2013). Reduksi kalsium oksalat dengan perebusan menggunakan larutan $\mathrm{NaCl}$ dan penepungan untuk meningkatkan kualitas sente (Alocasia macrorrhiza) sebagai bahan pangan. Jurnal Teknologi Kimia dan Industri, 76-83.

Dewanto, J., \& Purnomo, B. H. (2009). Pembuatan Konyaku Dari Umbi Iles-Iles Program Studi D3 Teknik Kimia Jurusan Teknik Kimia. Universitas Stuttgart.

Faridah, A., \& Widjanarko, B. (2014). Penambahan tepung porang pada pembuatan mi dengan substitusi tepung mocaf ( modified cassava flour ) [ Addition of Porang Flour in Noodle as Mocaf Substitution ( Modified cassava Flour )]. https://doi.org/10.6066/jtip.2014.25.1.98

Maulina, F. D. A., Lestari, I. M., \& Retnowati, D. S. (2012). Pengurangan Kadar Kalsium Oksalat Pada Umbi Talas Menggunakan Nahco3: Sebagai Bahan Dasar Tepung. Jurnal Teknologi Kimia dan Industri, 1(1), 277-283.

Sutriningsih, A., \& Ariani, N. L. (2017). Efektivitas Umbi Porang (Amorphophallus Oncophillus) Terhadap Penurunan Kadar Glukosa Darah Penderita Diabetes Mellitus. Care: Jurnal Ilmiah Ilmu Kesehatan, 5(1), 48-58.

Sutrisno, A. (2011). Proses Penurunan Kadar Kalsium Oksalat Menggunakan Penepung" Stamp Mill" untuk Pengembangan Industri Kecil Tepung Iles-Iles (Amorphophallus muelleri Blume). Jurnal Pangan, 20(4), 331340.

Widari, N. S., \& Rasmito, A. (2018). penurunan kadar kalsium oksalat pada umbi porang (Amorphopallus oncophillus) dengan proses pemanasan di dalam larutan nacl reduction of oxalic calcium consentration in porang tubers (Amorphopallus oncophillus) by heating process in nacl solution, 13(September), 1-4. 